\title{
PARÂMETROS DE PROJETO E MÉTODOS VISUAIS PARA APO DE EDIFÍCIO EDUCACIONAL
}

VISBQP

UBERLANDIA 2019

\author{
NEGRIS DE SOUZA, Larissa \\ Universidade Estadual de Campinas, e-mail: larissanegris@gmail.com \\ KOWALTOWSKI, Doris Catharine Cornelie Knatz \\ Universidade Estadual de Campinas, e-mail: doris@fec.unicamp.br \\ WOOLNER, Pamela \\ Newcastle University, e-mail: Pamela.Woolner@newcastle.ac.uk
}

\begin{abstract}
RESUMO
No programa arquitetônico, uma das fases iniciais no processo de projeto, há levantamento de dados que auxiliam na proposição do projeto. Estes dados, de diversas naturezas, devem incluir resultados coletados por meio de Avaliação Pós-Ocupação (APO), feita tanto por observações do pesquisador, quanto por percepções dos usuários. A APO em edifícios educacionais deve buscar compreender estes ambientes que impactam no bom desenvolvimento das atividades de ensino e aprendizagem. Há dinâmicas na educação, e, portanto, o conceito de parâmetros de projeto (PPs) deve ser considerado. Este estudo avaliou a utilização de métodos visuais específicos em APO para retroalimentação de projetos, considerando a inclusão dos PPs como critério de avaliação. A aplicação foi feita com alunos de uma escola de Ensino Fundamental II no Reino Unido. Os resultados demonstram que métodos visuais fornecem informações mais completas e de maior impacto para a retroalimentação de projetos quando associadas aos PPs. Há base sólida para a seleção de imagens e posterior análise e compreensão das respostas dos participantes, bem como aplicações melhor definidas. O estudo contribui para 0 desenvolvimento de métodos visuais para APO de escolas ao inserir PPs, que são essenciais para a arquitetura escolar do século XXI.
\end{abstract}

Palavras-chave: Avaliação pós-ocupação, Arquitetura escolar, Programa arquitetônico, Parâmetros de projeto, Métodos visuais.

\begin{abstract}
The development of an architectural programme is an important part of the initial phases of a design process, where data is collected to guide the design solution search. Data, of different types, should include results of Post-Occupancy Evaluations (POE) from observations and users perceptions. POEs of educational buildings seek to understand these environments that impact on teaching and learning activities. Due to the dynamics in education, it is essential that the concept of design parameters (PPS) should be included in POEs. This study evaluated the use of specific visual POE methods for design feedback, including PPs as an evaluation criterion. The study was carried out with students from a secondary school in the UK. Results demonstrate that visual methods provide more complete information and have a greater impact on project feedback when associated with PPs. There is a solid basis for the selected images and the subsequent analysis and understanding of participants' responses as well as well defined applications. The study contributes to the development of visual POE methods for school building design by inserting PPs, which are essential for the 21 st-century school.
\end{abstract}

Keywords: Post-occupancy evaluation, School architecture, Architectural programming, Design patterns, Visual methods.

NEGRIS DE SOUSA, L.; KOWALTOWSKI, D. C. C. K.; WOOLNER, P. Parâmetros de projeto e métodos visuais para APO de edifício educacional. In: SIMPÓSIO BRASILEIRO DE QUALIDADE DO PROJETO NO AMBIENTE CONSTRUÍDO, 6., 2019, Uberlândia. Anais... Uberlândia: PPGAU/FAUeD/UFU, 2019. p. 1293-1304. DOl https://doi.org/10.14393/sbqp19117. 


\section{INTRODUÇÃO}

O programa arquitetônico, essencial para proposição projetual, está na fase inicial do processo de projeto, o qual é composto de diversas etapas com objetivos e produtos distintos (MOREIRA, 2007; KOWALTOWSKI; MOREIRA, 2011). Para encontrar soluções mais apropriadas é necessário também levantar dados de experiências anteriores, no que é chamado Análise Pós-Ocupação (APO). Essa coleta de informações relativas ao uso e funcionamento de edifícios deve ser feita tanto com foco na percepção do pesquisador quanto nas informações fornecidas pelos usuários.

Critérios de projeto existentes e não existentes são levantados e relacionados ao desempenho do edifício, compreendendo interações antes não previstas e aprofundando o entendimento da experiência do usuário (CLEMENTSCROOME, 2018). A avaliação dessas informações retroalimenta a próxima fase do processo de projeto (CLEMENTS-CROOME, 2018) e é essencial no auxílio à proposição do modelo. Algumas metodologias de levantamento de dados podem ser aplicadas na etapa de APO, como os métodos visuais, uma forma de estímulo à participação ativa, ao encorajar o envolvimento e gerar discussões junto aos usuários (CLARK et al., 2013).

A escola é um elemento de grande importância para a sociedade e a comunidade em que se insere, e a coleta dessas informações leva à criação de soluções projetuais mais adequadas, como defendem Ornstein et al. (2009). Ao projetar edifícios educacionais, além de questões técnicas, deve-se trabalhar também com a cultura e valores da escola e da comunidade na qual esta se insere, bem como com as demandas dos usuários. Esses aspectos são essenciais porque é necessário um entendimento holístico das tendências e dinâmicas da educação e das atividades pedagógicas realizadas, dentro de um determinado contexto. Boys (2011) destaca que o espaço é uma relação, e nunca pode existir significativamente sem os usuários e o contexto no qual se insere.

Além da participação e da opinião dos usuários, deve-se ter em mente um importante aspecto da arquitetura escolar do século XXI: os Parâmetros de Projeto (PPs) de Nair et al. (2013). Esses PPs foram desenvolvidos tendo em vista as dinâmicas da educação e as pedagogias do século XXI e apontam para novas configurações arquitetônicas das escolas. Os PPs são orientações gerais das características escolares que precisam ser considerados também durante a realização de APO, uma vez que funcionam como guias na melhor definição dos pontos principais a serem considerados dentro do método. Posteriormente, eles vêm a funcionar como base de decisões no programa arquitetônico. Os PPs de Nair et al. (2013) apontam tendências e, assim, avaliações precisam ser cientes destes novos aspectos da arquitetura escolar.

Este estudo, realizado no Estágio de Pesquisa no Exterior, é parte do Mestrado finalizado na UNICAMP. Trabalhou-se em conjunto com o CfLat (Research Centre for Learning and Teaching) - Universidade de Newcastle, Reino Unido. O objetivo foi avaliar a possibilidade de utilização de métodos visuais em APO e para retroalimentação de projetos, considerando a inclusão dos PPs como critério de avaliação. 


\section{AVALIAÇÃO PÓS OCUPAÇÃo PARA ESCOLAS}

Para um projeto escolar, o espaço físico tem um importante papel no desenvolvimento das atividades de ensino-aprendizagem e modificações no design destes ambientes, mesmo quando feitas por etapas, contribuem positivamente nas dinâmicas educacionais (SCHABMANN et al., 2016; VELOSO; MARQUES, 2017; LE et al., 2018). Segundo Kowaltowski (2011), o ambiente físico escolar é onde se desenvolve o processo de ensino e aprendizagem. E, para um espaço adequado ao ensino e aprendizagem da época em que se localizam, com respeito às necessidades individuais e do grupo, é preciso um processo que valorize a participação desses atores. Essa participação pode acontecer no desenvolvimento do programa arquitetônico, mas também ao serem realizadas atividades em edifícios existentes e ocupados, buscando entender esse uso e percepção do espaço.

A APO permite que sejam levantados detalhes de funcionamento antes não compreendidos por completo, uma vez que depende da observação mais próxima e vivência (ao serem considerados os usuários) do local. Essa metodologia de avaliação levanta características positivas e negativas, sucesso e falhas, com relação à aspectos funcionais, sistemas construtivos, manutenção, conforto ambiental e relações entre o ambiente construído e comportamento humano (ORNSTEIN, 2005; ORNSTEIN et al., 2009; TAYLOR, 2009). Com a APO são feitos diagnósticos dos aspectos funcionais do edifício que serão utilizados na realimentação de processos de projeto (FRANÇA, 2011 ). Com relação à arquitetura escolar, acredita-se que a metodologia de APO possa ser aprimorada para atender às demandas atuais da educação, e por este motivo a inclusão dos novos PPs também nessa etapa se faz necessária.

\subsection{Parâmetros de projeto}

Os 29 PPs escolar definidos por Nair et al. (2013), e estudados em profundidade por Souza (2018), vêm a auxiliar o projeto de edificações escolares (Figura 1). Sua base está nos patterns de Alexander et al. (1977): soluções de problemas recorrentes, passíveis de serem aplicados incontáveis vezes sem nunca serem repetidos pela maneira de uso. Esses parâmetros também podem ser vistos como orientações das características do objeto - no caso, a escola -, durante o processo de projeto, e são respostas funcionais ao problema colocado (MOREIRA, 2007).

Ao trabalhar com os novos PPs, leva-se em consideração principalmente a existência de ambientes de ensino mais flexíveis e adaptáveis. Transformam-se conceitos clássicos de salas de aula, busca-se a existência de áreas casuais de alimentação; espaços com tecnologia distribuída; locais para estudo individual ou introspecção como em Cave Spaces; elementos de assinatura local para cada edifício projetado e que fazem dele um lugar único; são repensados os corredores antes apenas de passagem, entre diversos outros aspectos. Características como transparência, iluminação, acústica e elementos de sustentabilidade também fazem parte das descrições dos PPs e devem ser considerados, no processo de projeto, não só pelos aspectos funcionais, mas também sob a luz de requisitos de desempenho de referências normativas. 


\begin{tabular}{|c|c|}
\hline $\begin{array}{l}\text { 1. Salas de aula, ambientes de ensino e } \\
\text { comunidades pequenas de aprendizado. }\end{array}$ & 16. Watering Hole Space \\
\hline 2. Entrada convidativa & 17. Cave Space \\
\hline $\begin{array}{l}\text { 3. Espaços de exposição dos trabalhos dos } \\
\text { alunos }\end{array}$ & 18. Projeto para múltiplas inteligências* \\
\hline $\begin{array}{l}\text { 4. Espaço individual para armazenamento } \\
\text { de materiais }\end{array}$ & 19. Iluminação natural \\
\hline 5. Laboratórios de Ciências e Artes & 20. Ventilação natural \\
\hline 6. Arte, música e atuação & 21. lluminação, cor e aprendizagem \\
\hline 7. Área de educação física & 22. Elementos de sustentabilidade \\
\hline 8. Áreas casuais de alimentação & 23. Assinatura local \\
\hline 9. Transparência & 24. Conexão com a comunidade \\
\hline 10. Vistas interiores e exteriores & 25. Banheiros como os de casa \\
\hline 11. Tecnologia distribuída & 26. Professores como profissionais \\
\hline $\begin{array}{l}\text { 12. Conexão entre espaços externos e } \\
\text { internos }\end{array}$ & $\begin{array}{l}\text { 27. Recursos de aprendizado compartilhados } \\
\text { e biblioteca }\end{array}$ \\
\hline 13. Mobiliários confortáveis & 28. Proteção e segurança \\
\hline 14. Espaços flexíveis & 29. Síntese dos parâmetros \\
\hline 15. Campfire Space & \\
\hline
\end{tabular}

"Considera-se que existem oito inteligências: verbal-linguística, lógico-matemática, musical, corporalcinestésica, visual-espacial, naturalista, interpessoal, intrapessoal.

\section{Figura 1 - Parâmetros de projeto -}

Fonte: NAIR et al. (2013)

\subsection{Métodos visuais}

Os métodos visuais, segundo Prosser (2007), trabalham com produção, organização e interpretação de imagens. Para Woolner et al. (2010), esses métodos se mostram apropriados para a investigação da experiência dos usuários em um ambiente escolar. Essa experiência está relacionada ao contexto de utilização e escolhas dos usuários e Kim et al. (2016) veem essa compreensão ainda pouco explorada.

As imagens, de acordo com Harper (2002), despertam elementos da consciência humana mais profundos do que palavras, extraindo mais informações. O grupo de pesquisa CfLaT trabalha com essa abordagem e acreditam que estas afloram 0 interesse dos participantes na atividade desenvolvida, de uma forma descontraída e que facilita o desenvolvimento de discussões. Clark et al. (2013) acreditam que, dessa maneira, é possível estabelecer mais conexões, tanto entre os usuários participantes, quanto sobre as ideias discutidas, auxiliando na compreensão de seus pontos de vista e necessidades. Assim, acredita-se que a pesquisa com métodos visuais se mostra aplicável tanto em um processo participativo de projeto, quanto na metodologia APO, para compreender mais profundamente quem são os usuários, como reagem frente a algumas questões e o que esperam do projeto.

\subsubsection{Diamond Ranking}

Uma das maneiras de se trabalhar com métodos visuais é pelo uso da ferramenta de Diamond Ranking. Ao ranquear itens e discutir sobre as escolhas realizadas, é exigido dos participantes que deixem claro os motivos que levaram a determinados posicionamentos, organizando as informações que estão presentes em suas mentes (CLARK et al., 2013). Dessa maneira, é possível compreender o nível de importância/uso/percepção de cada elemento apresentado. 
Atividades realizadas dessa maneira são tradicionalmente utilizadas em escolas, com alunos para explorar seus valores, posicionamentos, sentimentos dentro de determinado assunto. Entretanto, pela experiência das autoras Clark et al. (2013), que fazem parte do CfLaT, esse método pode ser aplicado em uma variedade de panoramas, com participantes e objetivos diferentes. $O$ critério de seleção das imagens pelos participantes, porém, permanece, de acordo com as descrições fornecidas pelas autoras: interessante, importante, melhor ou significante, entre outras.

\subsubsection{Análise de plantas-baixas}

Esta análise ocorre em função da classificação, por cores, dos níveis de importância que os participantes dão aos ambientes escolares. Essa análise é especialmente importante ao se trabalhar com arquitetura e reconhecimento de ambientes pelos usuários, auxiliando o levantamento de dados sobre aspectos relacionados ao uso do edifício e, por consequência fornecendo informações que podem vir a facilitar a criação de um programa arquitetônico para construções novas ou uma reforma posterior.

\section{MATERIAIS E MÉTODOS}

A pesquisa teve um caráter exploratório e foi realizada por meio de Estudo de Caso. $O$ estudo de caso foi realizado com uma escola de ensino fundamental II (Secondary Schools) no Reino Unido (escolas próximas à sede da pesquisa Universidade de Newcastle upon Tyne) e as coletas de dados foram realizadas de acordo com permissões inglesas e acompanhadas pelo CfLaT. As primeiras visitas foram realizadas utilizando o método walkthrough, acompanhado de um dos membros da Local Authority de North Tyneside (órgão responsável pelo gerenciamento de escolas da região e do orçamento governamental destinado a elas) que tem como base de trabalho a escola selecionada. Neste primeiro momento observou-se o funcionamento geral da escola, suas características arquitetônicas - com base nos PPs.

Na terceira visita foram coletados de dados baseadas nos métodos visuais. As atividades foram realizadas com 12 estudantes dos $7^{\circ}$ e $9^{\circ}$ anos, divididos em duplas. A primeira atividade foi o Diamond Ranking, no qual 9 imagens foram selecionadas mostrando espaços escolares com características diversas de modo que os alunos participantes refletissem sobre estes elementos e considerando possibilidades para sua própria escola (utilizado para compreender nuances relacionadas à percepção dos alunos às características apresentadas e sua reação a elas). As imagens são apresentadas na Figura 2, onde há descrição do foco considerado para sua escolha, que teve como base as características e ambientes dos PPs.

Os parâmetros possuem suas características bem definidas por Nair et al. (2013) e Souza (2018). Assim, a proposta foi de incluir, na coleção de imagens, o máximo de PPs (observando suas características individuais) quanto possível. Trabalhou-se de modo especial com os parâmetros salas de aula, ambientes de ensino e pequenas comunidades; espaço individual para armazenamento; transparência; mobiliários confortáveis; espaços flexíveis; Watering Hole Space; Cave Space; projeto para múltiplas inteligências. Focou-se também em variações de cor, acabamento e forma dos ambientes. Foi pedido aos alunos que fizessem comentários de suas escolhas para auxiliar na compreensão do 
posicionamento das imagens. Posteriormente foi realizada a atividade de análise de planta baixa da escola. Os alunos, com posse de um panorama ampliado de possibilidades pela atividade anterior, deveriam avaliar os ambientes escolares como eficazes (em verde) e não eficazes (em vermelho) e discutir entre si os pontos que estavam sendo destacados.

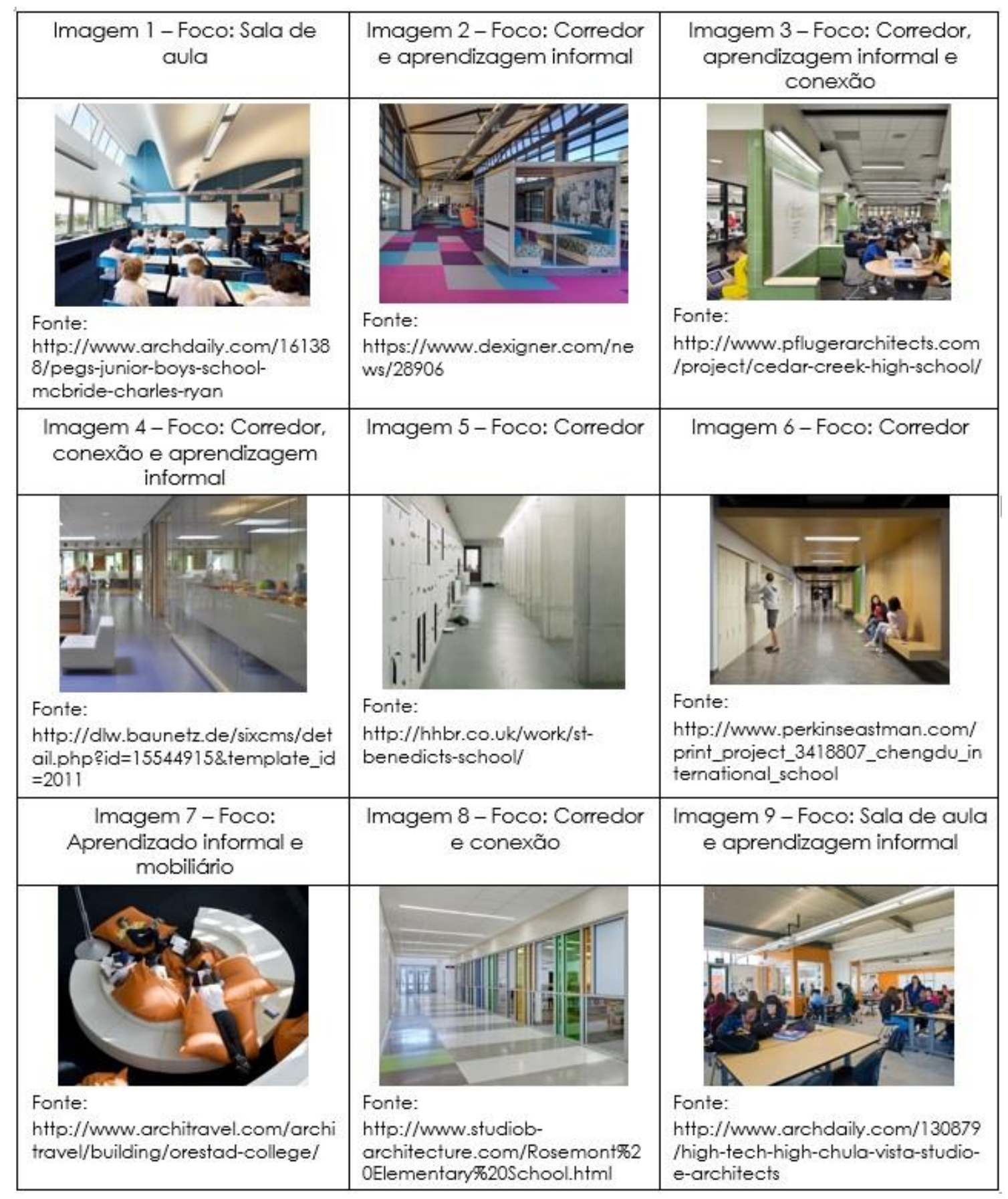

Figura 2 - Seleção de imagens para Diamond Ranking -

Fonte: Organizada pelas autoras

Para serem analisados os padrões de escolha em ambas as atividades, os Diamond Rankings gerados foram compilados em gráficos apresentando a frequência de ranqueamento das imagens em cada uma das linhas do diagrama: topo, alto, meio, baixo, inferior, e os pontos nas plantas baixas foram sobrepostos em arquivo único. Neste momento, os PPs são base para 
compreender características de projeto existentes na escola, como são avaliados pelos alunos, além de características consideradas positivas para serem acrescentadas em possíveis projetos futuros (tanto de reforma da escola visitada, quanto para novos projetos).

\section{RESULTADOS}

Com a coleta de dados obteve-se dois tipos de informação: análises dos Diamond Rankings, que dizem respeito ao modo como os alunos veem os parâmetros de projeto escolares e sua possível inserção em um projeto de reforma na escola; e análise de plantas baixas com relação à eficácia dos espaços.

O edifício selecionado de uma Secondary School do RU atende 850 alunos, construída na década de 1960 e reformada em 2005. Buscou-se ampliar a área construída pela necessidade de atender mais alunos. Desse modo, foram preenchidos espaços vazios da escola e melhorar a funcionalidade de ambientes (de modo especial os laboratórios de ciência e quadra de esportes e refeitório). Houve ainda redução de ruídos de impacto pelo uso de carpetes nos corredores e acréscimo de área para atender à comunidade local (academia e ginásio). Questões de segurança também foram melhoradas. A escola se divide em alas, por departamento, como mostra a Figura 3.

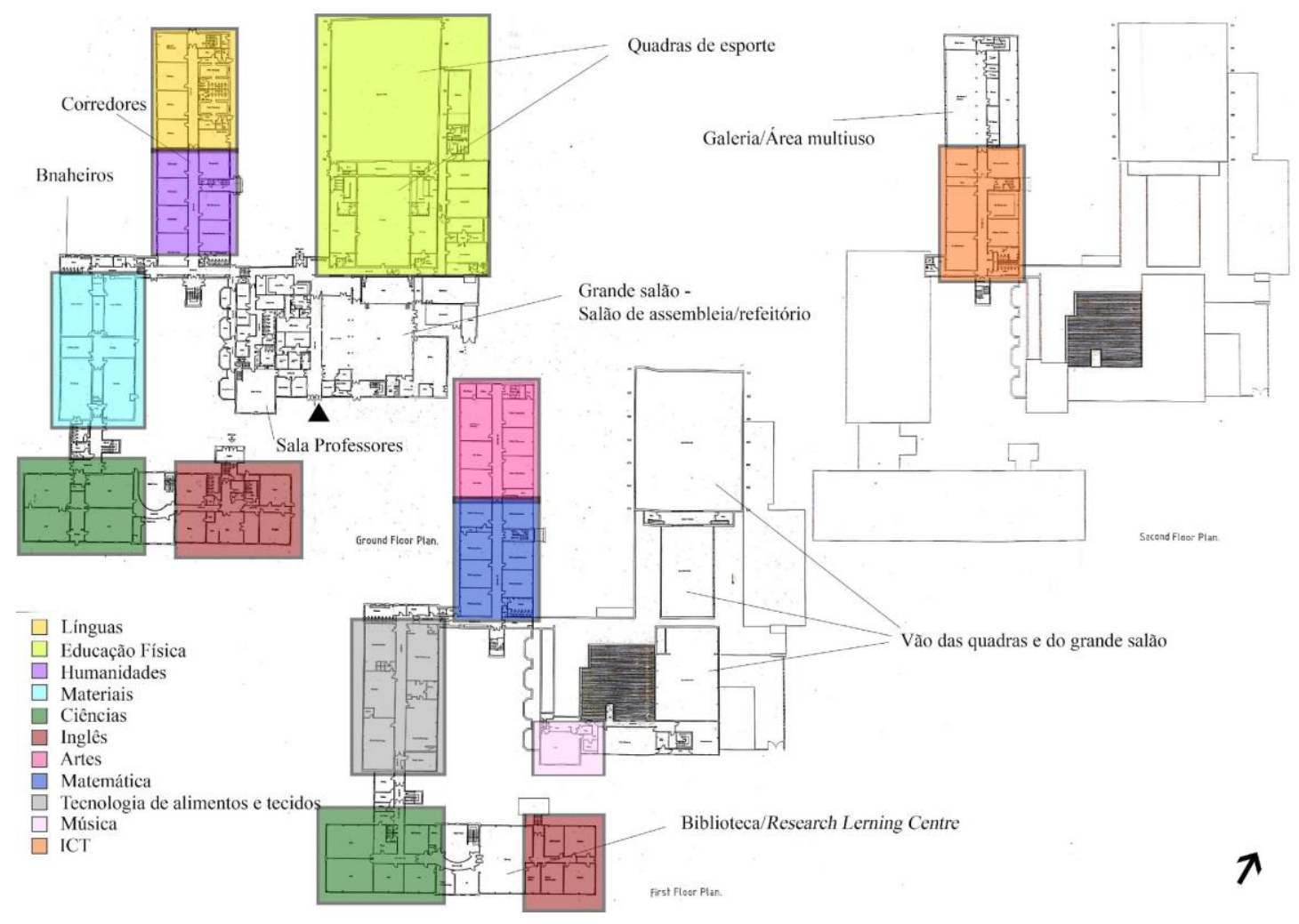

Figura 3 - Planta baixa da escola com divisão por departamento Fonte: Autoras (2017)

Na escola existem ambientes diversificados pela demanda curricular, mas que estes ainda utilizam poucos dos PPs escolares do século XXI. Observou-se seis PPs: espaços para educação física (forte aspecto da escola, que também funciona como um centro de treinamento de professores dessa área); 
Campfire Space (existência de um local de apresentações); assinatura local (o que se conecta aos valores da escola com relação ao seu edifício original e a expressão da pedagogia utilizada em sua composição arquitetônica); conexão com a comunidade; recursos de aprendizado compartilhados e biblioteca (com conexão visual e transparência na área multiuso e recursos variados tanto nesta área quanto na biblioteca - Learning Resource Centre, LRC) e proteção e segurança.

Outros 15 parâmetros foram encontrados parcialmente, o que significa dizer que foram encontrados apenas em poucas áreas da escola (não representando uma cultura escolar) ou não atendem a todos os aspectos de suas respectivas descrições. Dentre eles estão: transparência (vista apenas na área multiuso, na conexão do refeitório com o corredor e em uma área do LRC); tecnologia distribuída (apesar de aparelhos de projeção existirem em todas as salas de aula e salas de suporte com computadores estarem disponíveis em todos os departamentos, a distribuição geral ainda é limitada) e áreas de exposição de trabalho (que a escola possui ao serem considerados os corredores, mas são pouco utilizados).

Na atividade de Diamond Ranking foram gerados 6 diagramas. A Figura 4 apresenta o resultado de uma dupla. Na Figura 5 está o gráfico da frequência de imagens/linha e isso permite tirar conclusões sobre o motivo das opções. Os alunos fizeram comentários sobre cores/acabamento dos espaços, iluminação, conforto, conexões por transparência, tecnologia, trabalho em grupo e estudo individual e espaço para armazenamento. Estes aspectos fazem parte das descrições dos PPs, direta ou indiretamente, o que indica sua importância no projeto arquitetônico.

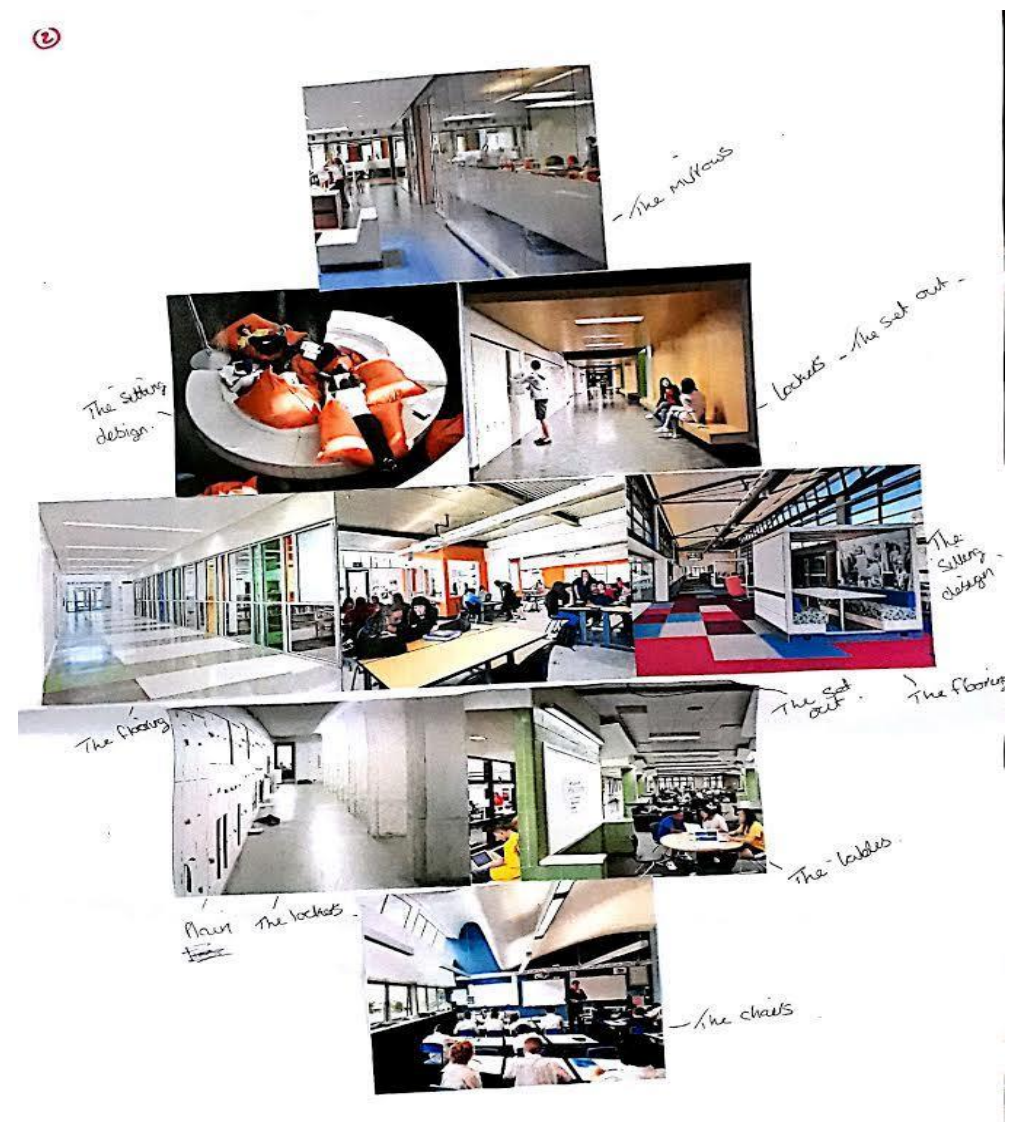

Figura 4 - Diamond Ranking de uma dupla - 


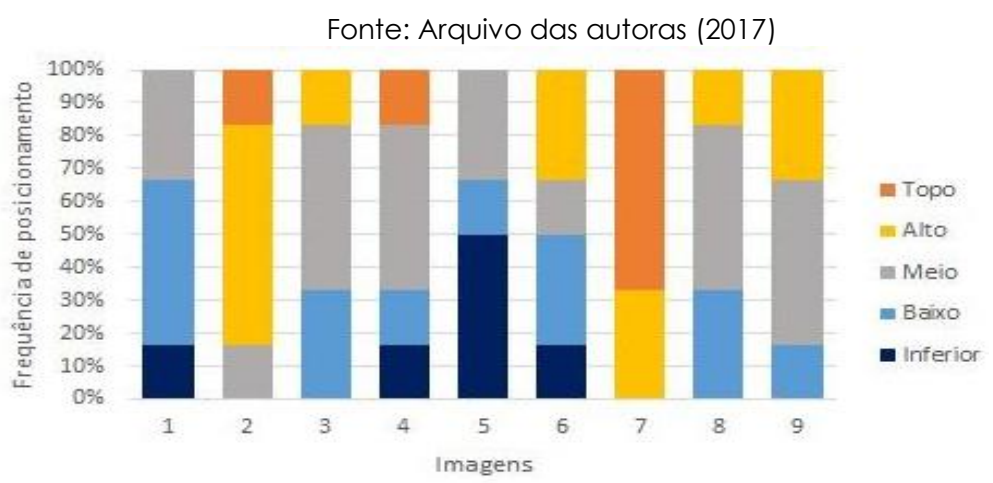

Figura 5 - Gráfico de resultado dos Diamond Rankings Fonte: Arquivo das autoras (2017)

A imagem 5 foi mais frequentemente posicionada em "inferior", mesmo apresentando característica valorizada pelos alunos: espaço para armazenamento. Foram feitas observações que o espaço não é interessante pela falta de cores e tipo de acabamento. A imagem 7 foi a que mais apareceu no "topo", por representar um local de mobiliário confortável e importante para descanso (elemento que pode ser melhor avaliado de modo a compreender o que os alunos entendem pelo uso de espaços com assentos confortáveis e informais). A imagem 2, mais vezes posicionada na seção "alta", foi classificada como clara, vibrante, com boas cores (destaca-se o piso) e com locais para se sentar confortavelmente e interessantes para se fazer tarefas/estudar.

A atividade com as plantas baixas foi compilada em arquivo único (Figura 6). A partir das discussões foi possível compreender o posicionamento dos pontos relativos aos espaços eficazes (em verde) e não-eficazes (em vermelho). Os pontos comentados foram destacados com as linhas de chamada.

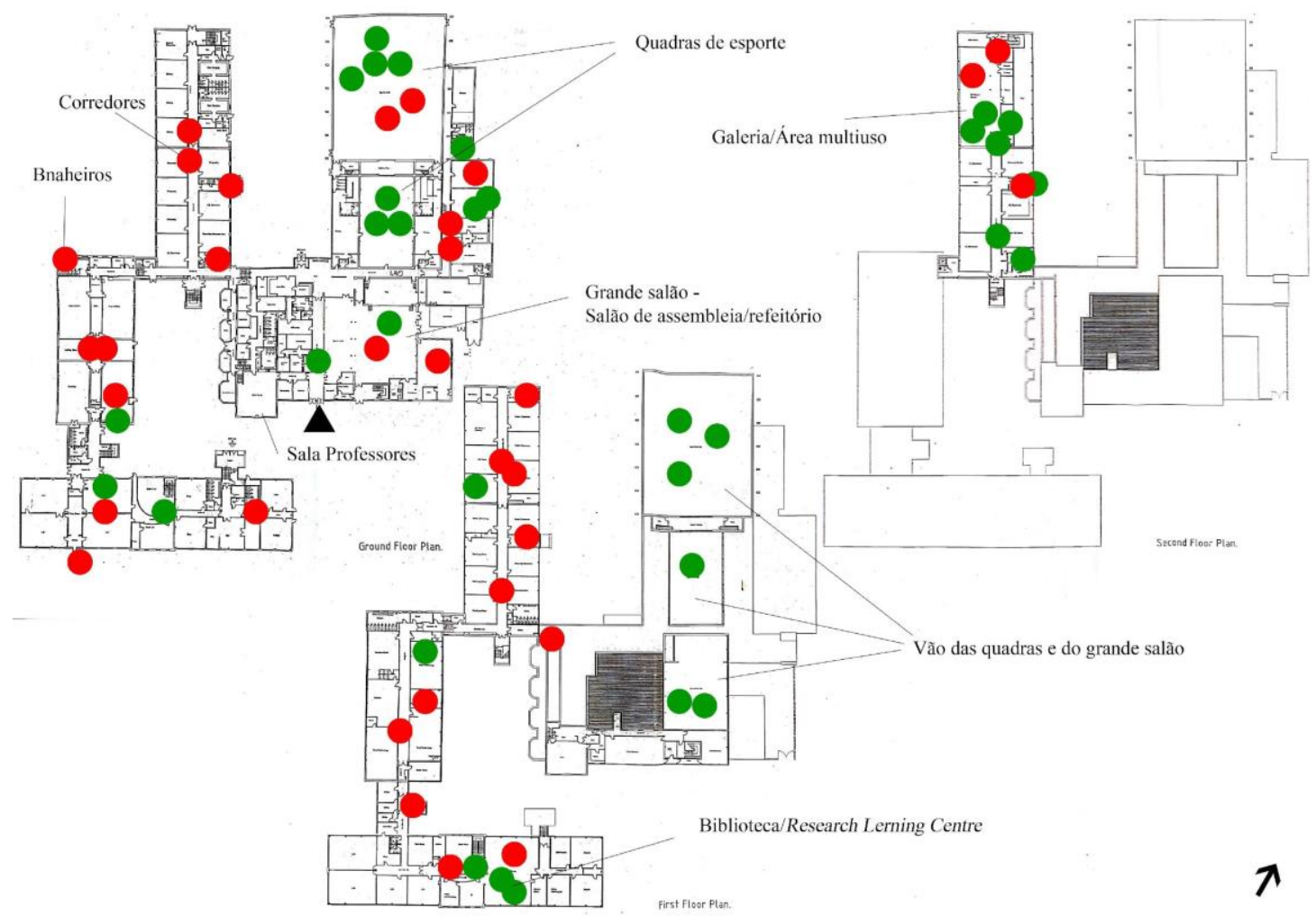

Figura 6 - Compilação das plantas baixas - 
$\mathrm{Na}$ Figura 5, destacam-se: os corredores, considerados pequenos para sustentar períodos de maior fluxo e os banheiros de tamanho e aspecto inadequado. A maioria das classificações na quadra de esportes apontou que essa área é eficaz. O grande salão, importante foco na reforma, foi pouco analisado, tendo recebido um marcador vermelho. A galeria, com características mais próximas dos PPs, foi avaliada majoritariamente como eficaz pelo tamanho e pelos ambientes oferecidos: grande salão (espaço flexível), e salas com transparência (music suite, iMac suite, Macbook suíte e iPad suite). O learning research centre foi classificado, em geral, como eficaz. Não houve observações específicas com relação às salas de aula.

\section{DISCUSSÃO}

Observou-se que, levando em consideração as descrições dos PPs, a escola apresenta muitas características consideradas importantes para edifícios educacionais incluídas, ou melhoradas, com a reforma. Isso demonstra uma preocupação de atualização dos ambientes escolares, mesmo que a reforma tenha acontecido há anos e não se tivesse conhecimento do conceito de PPs apresentado neste estudo. O que se discute a partir dessa observação é que os alunos conseguem perceber exatamente as características relacionadas a esse conceito, e que elas fazem falta quando não existem.

A partir dos resultados do Diamond Ranking é possível destacar que os alunos definiram como mais significativas as características relacionadas a parâmetros ainda não presentes na escola, o que mostra que gostariam de ter acesso à ambientes que apresentassem esses aspectos. Para eles, o trabalho com cores é estimulante, bem como a escolha dos móveis e a iluminação. A atividade de ranqueamento também permitiu que os estudantes se envolvessem ativamente na discussão, criando comparações com o que existe e aquilo que gostariam. Essas opiniões são importantes para toda metodologia APO e se mostrou eficiente nesse sentido.

As observações relacionadas às transparências presentes nas imagens do Diamond Ranking contribuem para a análise relacionada às conexões interiores - e entre estes espaços e o exterior. Uma vez que esta característica foi considerada positiva nas imagens, trabalhar com elas e outros tipos de conexões visuais e físicas também com o espaço externo em projetos futuros pode significar maior satisfação e motivação com relação ao edifício. Isto também deve poder contribuir para a proteção e segurança dos alunos (pelo controle visual passivo que este aspecto permite).

A análise por plantas aponta espaços que se destacam pelo seu aspecto funcional. Neste momento também foram indicados pontos que vão de encontro com os PPs. Os corredores foram considerados espaços ineficazes pela superlotação em períodos de troca de aula e isto está ligado ao modo como estes espaços são vistos e usados: locais de passagem, sem aproveitar as potencialidades de criação de espaços de aprendizagem informal, o que está ligado a parâmetros ainda não presentes na escola (Watering Hole e Campfire Space), ou pouco presentes (transparência). Essas características foram exemplificadas na imagem 4 da Figura 2, e esta imagem foi majoritariamente classificada nas partes meio-topo do diagrama. 


\section{CONSIDERAÇÕES FINAIS}

A compreensão, pela APO, de preferências e comportamentos humanos auxilia a elaboração de projetos mais conectados às necessidades contemporâneas. Uma das maneiras de coleta dessas informações é através de atividades que envolvam usuários. Os métodos visuais aplicados neste estudo beneficiaram a determinação dos pontos valorizados pelos usuários e auxiliaram na compreensão de aspectos de projetos educacionais, a partir da análise de uma situação real. Os dados coletados objetivam a produção mais eficiente de soluções e quanto mais tempo e maior espaço amostral na aplicação da metodologia, mais informações são coletadas, facilitando o processo de identificação de demandas. A inclusão dos PPs em atividades de APO, contribuição do estudo, possibilita coletas de informação e sua compreensão conectada às necessidades contemporâneas educacionais. Pesquisas no sentido de compreender o uso dos parâmetros no processo de projeto, também podem aprofundar análises que relacionam estes elementos aos requisitos de desempenho de referências normativas, buscando observar como os PPs também podem auxiliar no pensamento e inclusão de elementos essenciais das normas.

\section{AGRADECIMENTOS}

À Fapesp: Processos 2016/11479-3 e 2016/25514-0, ao CfLaT e à escola do Estudo de Caso.

\section{REFERÊNCIAS}

ALEXANDER, C. et al. A pattern language: towns, buildings, construction. New York: Oxford University Press, 1977.

BOYS, J. Towards Creative Learning Spaces: Rethinking the Architecture of PostCompulsory Education. Oxon: Routledge, 2011.

CLARK, J. et al. Making Connections: Theory and Practice of Using Visual Methods to Aid Participation in Research. Newcastle upon Tyne, 2013.

CLEMENTS-CROOME, D. The role of feedback in building design 1980-2018 and onwards. Building Services Engineering Research and Technology, 9 nov. 2018.

FRANÇA, A. J. G. L. Ambientes Contemporâneos para o Ensino-Aprendizagem: Avaliação Pós-Ocupação aplicada a três Edifícios Escolares Públicos, situados na Região Metropolitana de São Paulo. 2011. Dissertação (Mestrado). Faculdade de Arquitetura e Urbanismo Universidade de São Paulo, São Paulo. 2011.

HARPER, D. Talking about pictures: A case for photo elicitation. Visual Studies, v. 17, n. 1, p. 13-26, 1 jan. 2002.

KIM, T. W. et al. Space choice, rejection and satisfaction in university campus. Indoor and Built Environment, 24 ago. 2016.

KOWALTOWSKI, D. C. C. K. Arquitetura escolar: o projeto do ambiente de ensino. São Paulo: Oficina de Textos, 2011.

KOWALTOWSKI, D. C. C. K.; MOREIRA, D. de C. O programa arquitetônico. In: KOWALTOWSKI, D. C. C. K.; et al. (Orgs.). O processo de projeto em arquitetura: da teoria à tecnologia. São Paulo: Oficina de Textos, 2011. 
LE, A. T. H. et al. Sustainable refurbishment for school buildings: a literature review. International Journal of Building Pathology and Adaptation, 11 jun. 2018. MOREIRA, D. C. Os princípios da síntese da forma e a análise de projetos arquitetônicos. 2007. Tese (Doutorado) - Faculdade de Engenharia Civil, Arquitetura e Urbanismo, Universidade Estadual de Campinas, Campinas, 2007. NAIR, P. et al. The Language of School Design: Design Patterns for 21 st Century Schools. Minneapolis: DesignShare, 2013.

ORNSTEIN, S. W. et al. Improving the quality of school facilities through building performance assessment: Educational reform and school building quality in São Paulo, Brazil. Journal of Educational Administration, v. 47, n. 3, p. 350-367, 8 maio 2009.

PROSSER, J. Visual methods and the visual culture of schools. Visual Studies, $v$. 22, n. 1, p. 13-30, 1 abr. 2007.

SCHABMANN, A. et al. The relevance of innovative school architecture for school principals. School Leadership \& Management, v. 36, n. 2, p. 184-203, 14 mar. 2016.

SOUZA, L. N. de. Arquitetura Escolar, Parâmetros de Projeto e Modalidades de Aprendizagem. 2018. Dissertação (Mestrado). Faculdade de Engenharia Civil e Arquitetura, Universidade Estadual de Campinas, Campinas. 2018.

TAYLOR, A. P. Linking Architecture and Education: sustainable design for learning environments. New Mexico: University of New Mexico Press, 2009.

VELOSO, L.; MARQUES, J. S. Designing science laboratories: learning environments, school architecture and teaching and learning models. Learning Environments Research, v. 20, n. 2, p. 221-248, 1 jul. 2017.

WOOLNER, P. et al. Pictures are necessary but not sufficient: Using a range of visual methods to engage users about school design. Learning Environments Research, v. 13, n. 1, p. 1-22, 1 mar. 2010. 